\title{
Una revisión del protocolo Draw-a-Scientist-Test (DAST)
}

\author{
Radu Bogdan Toma ${ }^{1 a}$, Ileana María Greca ${ }^{1 b}$, Martha Lucía Orozco Gómez ${ }^{2 c}$ \\ ${ }^{1}$ Departamento de Didácticas Especificas, Área de Didácticas Experimentales. Universidad de Burgos, \\ España. \\ ${ }^{2}$ Departamento de Ciencias de la Educación, Area de Didáctica y Organización Escolar. Universidad de \\ Burgos, España. \\ ‘rbtoma@ubu.es,'imgreca@ubu.es,'mlorozco@ubu.es
}

[Recibido: 23 Noviembre 2017. Revisado: 7 Abril 2018. Aceptado: 9 Junio 2018]

\begin{abstract}
Resumen: Durante décadas, numerosas investigaciones han identificado la existencia de imágenes estereotipadas sobre los científicos mediante el empleo del método Draw-a-Scientist-Test (DAST). No obstante, las limitaciones metodológicas asociadas al DAST cuestionan los resultados obtenidos y resaltan la necesidad de desarrollar nuevos protocolos para evaluar las concepciones de los estudiantes acerca de los científicos. En este trabajo, tras revisar las deficiencias metodológicas del DAST, se proponen algunas modificaciones al protocolo original probadas en una prueba piloto con 149 estudiantes de $2^{\circ}$ a $6^{\circ}$ curso de Educación Primer de diversidad cultural. Los resultados iniciales muestran que las modificaciones realizadas ayudan a reducir algunos de los problemas metodológicos identificados en el uso del DAST, permitiendo identificar e interpretar de manera más fiable las concepciones de los estudiantes sobre los científicos.
\end{abstract}

Palabras clave: imagen de científico, DAST, estereotipos sobre ciencia, educación primaria, diversidad cultural

\section{A revision of the Draw-a-Scientist-Test (DAST)}

Abstract: For decades, studies have shown the existence of a stereotypical image of scientist between children among the world using the Draw-a-Scientist-Test (DAST) method. However, the methodological limitations associated with the DAST question the results obtained and highlight the need to develop new protocols to evaluate students' conceptions about scientists. In this paper the methodological deficiencies of the DAST instrument are reviewed and some changed made to the original protocol are described. The pilot test carried out with 149 students of cultural diversity enrolled in $2^{\text {nd }}$ to $6^{\text {th }}$ grades of Elementary School shows that this modification allows a more reliable identification and analysis of students' conceptions, reducing some of the methodological problems identified in the use of DAST.

Keywords: image of scientist, Draw-a-Scientist-Test, science stereotypes, primary school, cultural diversity

Para citar este artículo: Toma, R. B., Greca, I. M., Orozco Gómez, M. L. (2018) Una revisión del protocolo Draw-aScientist-Test (DAST). Revista Eureka sobre Enseñanza y Divulgación de las Ciencias 15(3), 3104. doi: 10.25267/Rev_Eureka_ensen_divulg_cienc.2018.v15.i3.3104

\section{Introducción}

Varios estudios muestran que los estudiantes que poseen concepciones negativas sobre los científicos son poco proclives a interesarse por carreras científicas (Finson 2002; McCann y Marek 2016). La exploración y comprensión de estas percepciones es relevante para la comunidad educativa, habiéndose desarrollado numerosas investigaciones de diagnosis y análisis de las concepciones de los estudiantes. El uso del Draw a Scientist Test (DAST) (Chambers 1983) se ha convertido en una práctica común para investigar estas percepciones, especialmente con niños. Usando este método, los investigadores han documentado que los estudiantes tienden a retratar a los científicos como varones de mediana o avanzada edad, con aspecto descuidado, confinados en un laboratorio, rodeados de instrumentos y disoluciones peligrosas y quienes, además, desarrollan experimentos de dudosa moralidad (DeWitt, Archer y Osborne 2013; Ruiz-Mallén y Escalas 2012). 
No obstante, los resultados obtenidos están siendo cuestionados por inconsistencias metodológicas relacionadas con los instrumentos y los procedimientos utilizados (Andersen, Krogh y Lykkegaard 2014; Losh, Wilke y Pop 2008; Reinisch, Krell, Hergert, Gogolin y Krüger 2017). Dado que la persistencia de estos estereotipos puede afectar al desarrollo de vocaciones científicas y al interés por la ciencia, es necesario desarrollar nuevos protocolos de administración y análisis para diagnosticar de forma más eficaz las percepciones de las niñas y niños sobre los científicos.

El objetivo de este trabajo es presentar algunas modificaciones realizadas al DAST que han mostrado ser efectivas para superar algunas de las principales limitaciones relacionadas con el instrumento en sus versiones anteriores. Para ello, se realiza en primer lugar una revisión detallada de la literatura especializada en el diagnóstico de las imágenes sobre los científicos, prestando especial énfasis a las limitaciones relacionadas con el uso del DAST en su versión original. Posteriormente, se describen las modificaciones realizadas y se presentan los resultados de un estudio piloto desarrollado con 149 estudiantes de Educación Primaria con diferentes antecedentes culturales y de diferentes edades. Finalmente, se discute la eficacia y las limitaciones de los cambios propuestos y se señalan vías para futuras investigaciones.

\section{Revisión de la literatura}

La hipótesis que defiende la existencia de percepciones estereotipadas de los científicos entre los estudiantes fue propuesta inicialmente en la década de los años 50 del siglo XX por Mead y Métraux (1957), cuyo estudio reveló una imagen de científico como "Un hombre que lleva una bata blanca y trabaja en un laboratorio. Es de mediana o avanzada edad y usa gafas. Está rodeado de instrumentos: tubos de ensayo, quemadores bunsen, frascos y botellas, tubos de vidrio y máquinas extrañas con diales. Pasa sus días haciendo experimentos" (Mead y Métraux 1957, pp. 386-387 [traducción propia]). Desde entonces, esta descripción es considerada la imagen estereotipada clásica de un científico.

Décadas más tarde, Chambers (1983) desarrolló el Draw-a-Scientist Test (DAST), un instrumento cuya administración no requería respuestas escritas pues solicitaba a los participantes dibujar un científico. En el análisis posterior, Chambers identificó siete atributos que aparecían sistemáticamente en los dibujos: bata de laboratorio (generalmente blanca), gafas, vello facial (barba, bigote o patillas anormalmente largas), símbolos de investigación (instrumentos científicos), símbolos de conocimientos (libros y librerías), tecnología (productos de la ciencia) y frases relevantes (¡Eureka! y similares). Chambers también identificó la presencia de criaturas místicas y personajes literarios (Frankenstein; Doctor Jekyll y el Señor Hyde), representaciones mágicas de laboratorios alquímicos y científicos locos practicando torturas. Años más tarde, Finson Beaver y Cramond (1995) desarrollaron la rúbrica DAST-C (DAST checklist) añadiendo nueve indicadores adicionales que incorporaban la raza y el sexo de los científicos, así como otros elementos repetidamente presentes en estudios anteriores pero que no fueron incorporados a la lista original del instrumento. Adaptaciones más recientes del DAST original son el E-DAST (Enhanced Draw-A-Scientist Test), que consiste en la realización de un conjunto de tres dibujos sobre los científicos para estudiar cómo varían las concepciones en sucesivas representaciones (Farland-Smith y McComas 2006) o el mDAST (modified DAST), que solicita a los estudiantes incluir explícitamente información sobre la apariencia, el lugar de trabajo y la actividad, permitiendo así obtener aquellos datos menos probables de ser incluidos por los alumnos en sus dibujos (Farland-Smith 2012).

En conjunto, tanto la versión original como las sucesivas adaptaciones del DAST muestran que los estereotipos sobre los científicos son persistentes y que estos se repiten en todos los niveles académicos, acentuándose y consolidándose a medida que aumenta el nivel escolar 
(Medina-Jerez, Middleton y Orihuela-Rabaza 2011; Özel 2012; Ruiz-Mallén y Escalas 2012). Así, en los dibujos predomina la presencia de científicos varones, de rasgos caucásicos, con gafas y vello facial, que visten batas de laboratorio y que mayormente realizan trabajos relacionados con la química (DeWitt et al. 2013; Finson 2002; Özgelen 2012; Türkmen 2008; Vázquez y Manassero 1998; Zhai, Jocz y Tan 2014). Además, varios estudios indican que los niños poseen concepciones más estereotipadas que las niñas (Newton y Newton 1998; RuizMallén y Escalas 2012) y que la cultura y procedencia de los participantes tiene un alto impacto en la formación de imágenes de científicos. Por ejemplo, (Farland-Smith 2009) registró diferencias en las representaciones de los estudiantes estadounidenses, que concibieron a los científicos trabajando en laboratorios con productos químicos mientras que las representaciones de estudiantes de origen asiático mostraban científicos en fábricas creando robots.

\section{Limitaciones metodológicas del DAST}

En los últimos años, las críticas relacionadas con el uso del DAST para la identificación de concepciones sobre los científicos han ido en aumento, discutiéndose si los estereotipos pueden resultar de la falta de habilidad artística y no de los prejuicios arraigados, o si las imágenes dibujadas reflejan los estereotipos de la sociedad presentes en los medios de comunicación en lugar de la propia idea que poseen los estudiantes sobre los científicos. Losh et al. (2008) señalan la falta de consideración del diferente desarrollo madurativo entre niñas y niños como uno de los principales defectos del DAST. Así, las diferencias en los dibujos pueden deberse al mayor control fino de las niñas en comparación con los niños (Boyd y Bee 2006) y no a una diferencia de concepciones, sucediendo lo mismo con los estudiantes con mayor talento artístico o aquellos de niveles superiores.

Otras críticas están relacionadas con la interpretación de los dibujos. Losh et al. (2008) encontraron una gran cantidad de representaciones en las que el sexo de los científicos mostraba un elevado grado de ambigüedad. Andersen et al. (2014), utilizando entrevistas, obtuvieron que, a diferencia de la mayoría de estudios anteriores que emplearon el DAST, muchas de las opiniones que tenían los estudiantes sobre los científicos eran realistas y los rasgos estereotipados solían ser positivos, como, por ejemplo, considerar que los científicos desean descubrir nuevos conocimientos, son curiosos, lógicos y analíticos.

Otra principal limitación está relacionada con la fiabilidad del protocolo DAST, en particular, con las diferentes formas de administrar el instrumento (solicitar un dibujo o varios) y con las instrucciones facilitadas que podrían introducir sesgo en la respuesta del participante. Maoldomhnaigh y Hunt (1988) solicitaron a 76 estudiantes de quinto nivel de Educación Primaria que realizaran varios dibujos de científicos. La frecuencia en la aparición de aspectos místicos y caricaturescos fue mayor en el segundo dibujo de los participantes, lo que parece mostrar que un mismo estudiante puede tener varias visiones sobre los científicos, y que un solo dibujo no es suficiente para captar la totalidad de las concepciones. Farland-Smith y McComas (2006) utilizaron un enfoque similar y su estudio reveló que en el 76\% de los casos, el primer dibujo de los estudiantes difiere significativamente de los posteriores. Maoldomhnaigh y Mhaolái (1990) pidieron a un grupo de participantes dibujar un científico y a otro grupo dibujar un hombre o una mujer científica. Los resultados mostraron que las instrucciones facilitadas alteraron significativamente el tipo de dibujos realizados por los participantes. Mientras que en el primer grupo tan solo el $28 \%$ de las niñas han dibujado científicas mujeres, en el segundo grupo el $49 \%$ de los dibujos de las niñas representaban a una mujer científica. 
En definitiva, el estudio de las concepciones de los estudiantes sobre los científicos ha de tener en cuenta los siguientes aspectos: (I) el desarrollo madurativo es diferentes en los niños y las niñas; (II) las habilidades artísticas son muy diferentes entre el alumnado; (III) las instrucciones en la administración del instrumento deben reducir el sesgo; y, (IV) el uso solo de dibujos puede ser insuficiente para captar la totalidad de la concepción de los estudiantes. Por lo tanto, existe una clara necesidad de desarrollar protocolos alternativos y mejorados para evaluar qué imagen de científico tienen los niños y las niñas de Educación Primaria.

\section{Descripción del nuevo protocolo}

Para superar algunas de las limitaciones relacionadas con el DAST, se propone un protocolo multidimensional en el que se estudia la imagen de los estudiantes a través de dos fases: una primera, cuantitativa, que consiste en realizar un dibujo sobre los científicos; y, una segunda fase, cualitativa que consta de preguntas cortas que se han de responder de forma escrita y una prueba de selección de imágenes. A través de estas fases, se pretende abordar cinco aspectos diferentes de las concepciones de los estudiantes: (I) apariencia de los científicos, (II) origen, (III) lugar de trabajo, (IV) actividad, y (V) forma en que realizan dicha actividad. La tabla 1 recoge qué limitaciones de las señaladas en la literatura pretenden reducir cada una de las fases del protocolo propuesto.

Tabla 1. Limitaciones del DAST que se pretenden reducir mediante el protocolo propuesto

\begin{tabular}{|c|c|c|c|}
\hline Limitaciones del DAST & Dibujo & $\begin{array}{c}\text { Preguntas } \\
\text { escritas }\end{array}$ & $\begin{array}{l}\text { Selección } \\
\text { de } \\
\text { imágenes }\end{array}$ \\
\hline Diferente desarrollo madurativo (Losh et al. 2008) & $\mathrm{x}$ & $\mathrm{x}$ & $\mathrm{x}$ \\
\hline Habilidades artísticas dispares (Losh et al. 2008; Reinisch et al. 2017) & $\mathrm{x}$ & $\mathrm{x}$ & $\mathrm{x}$ \\
\hline Sexo del científico ambiguo (Losh et al. 2008; Reinisch et al. 2017) & & $\mathrm{x}$ & $\mathrm{x}$ \\
\hline Edad del científico ambiguo (Reinisch et al. 2017) & & $\mathrm{x}$ & \\
\hline Etnia/nacionalidad del científico ambigua (Reinisch et al. 2017) & & $\mathrm{x}$ & $\mathrm{x}$ \\
\hline Dibujos socialmente reconocibles (Finson y Pederson 2011) & & $\mathrm{x}$ & $\mathrm{x}$ \\
\hline $\begin{array}{l}\text { Los dibujos proporcionan información limitada (Ehrlen, 2009; } \\
\text { Reinisch et al.,2017) }\end{array}$ & & $\mathrm{x}$ & $\mathrm{x}$ \\
\hline $\begin{array}{l}\text { Resultados dependientes de la administración del instrumento } \\
\text { (Farland-Smith y McComas 2006; Maoldomhnaigh y Mhaoláin } \\
\text { 1990; Maoldomhnaigh y Hunt 1988) }\end{array}$ & $\mathrm{x}$ & $\mathrm{x}$ & $\mathrm{x}$ \\
\hline $\begin{array}{l}\text { Posible existencia de más de una imagen de científico en cada } \\
\text { participante (Farland-Smith y McComas 2006; Finson et al. 1995) }\end{array}$ & $x$ & $x$ & $x$ \\
\hline
\end{tabular}

\section{Dibujo}

Se ha modificado la instrucción original "Dibuja un científico" (Chambers 1983, p. 256 [traducción propia]) por "Imagina que vas de viaje a ver cómo se hace ciencia. Dibuja quién hace ciencia, cómo es, dónde trabaja y qué hace", basada en Farland-Smith (2012). Esta instrucción solicita de manera explícita que se incluya en el dibujo información sobre la apariencia del científico, su trabajo y el lugar en el que lo realiza. Nótese que se ha suprimido la palabra "científico" dado que, en castellano, a diferencia del inglés, esta palabra hace referencia explícita al género masculino. Además, se ha evitado cualquier referencia a personas (p. ej. Dibuja a una persona que hace ciencia) a fin de evitar introducir sesgo en las representaciones y reducir en mayor medida las limitaciones asociadas con resultados dependientes de la forma en que se administra el instrumento (Farland-Smith y McComas 2006; Maoldomhnaigh y Mhaoláin 1990; Maoldomhnaigh y Hunt 1988). Otras modificaciones están relacionadas con la administración del protocolo. Se ha estandarizado los materiales disponibles, entregándose a cada estudiante cinco lápices de colores para reducir los problemas resaltados en la literatura 
con respecto a la diferencia de detalles dibujados por las niñas y los niños (Losh et al. 2008; Reinisch et al. 2017) y la falta de material para transmitir las propias concepciones (Reinisch et al. 2017).

Para evaluar esta dimensión del protocolo, se emplea una categorización (Tabla 2) adaptada a partir de Farland-Smith (2012), en la que se evalúan tres aspectos (apariencia, ubicación y actividad) de los dibujos en función de cuatro posibles concepciones (sensacionalista, tradicional-estereotipada, alternativa-no estereotipada, y aspectos imposibles de determinar por falta de información o dibujos no interpretables).

Tabla 2: Categorización para analizar los dibujos

\begin{tabular}{|c|c|c|c|c|}
\hline \multirow[b]{2}{*}{ Aspectos } & \multicolumn{4}{|c|}{ Concepciones } \\
\hline & $\begin{array}{c}\text { Imposible de } \\
\text { determinar }\end{array}$ & Sensacionalista & $\begin{array}{l}\text { Tradicional- } \\
\text { estereotipada }\end{array}$ & $\begin{array}{l}\text { Alternativa-no } \\
\text { estereotipada }\end{array}$ \\
\hline Apariencia & $\begin{array}{l}\text { Figuras de palo; } \\
\text { otra profesión; no } \\
\text { se puede } \\
\text { identificar. }\end{array}$ & $\begin{array}{c}\text { Caricatura; } \\
\text { monstruo; científico } \\
\text { loco. }\end{array}$ & $\begin{array}{c}\text { Varón caucásico; } \\
\text { bata de laboratorio; } \\
\text { mediana-avanzada } \\
\text { edad. }\end{array}$ & $\begin{array}{c}\text { Minorías étnicas; } \\
\text { extranjeros; mujeres }\end{array}$ \\
\hline $\begin{array}{l}\text { Actividad que } \\
\text { realizan }\end{array}$ & $\begin{array}{l}\text { No aparece; no se } \\
\text { puede identificar }\end{array}$ & $\begin{array}{l}\text { Actividades } \\
\text { peligrosas } \\
\text { (explosiones, fuego, } \\
\text { pociones); torturas. }\end{array}$ & $\begin{array}{l}\text { Propias de } \\
\text { laboratorio; } \\
\text { experimentos } \\
\text { químicos; trabajo } \\
\text { individual. }\end{array}$ & $\begin{array}{c}\text { Actividades } \\
\text { diferentes a las de un } \\
\text { laboratorio } \\
\text { convencional } \\
\text { (redacción); trabajo } \\
\text { grupal. }\end{array}$ \\
\hline $\begin{array}{l}\text { Lugar de } \\
\text { trabajo }\end{array}$ & $\begin{array}{l}\text { No aparece; no se } \\
\text { puede identificar. }\end{array}$ & $\begin{array}{l}\text { Sótano; cueva; } \\
\text { caverna; lugares } \\
\text { secretos. }\end{array}$ & $\begin{array}{l}\text { Laboratorio } \\
\text { tradicional, } \\
\text { particularmente de } \\
\text { química }\end{array}$ & $\begin{array}{c}\text { Lugares diferentes a } \\
\text { un laboratorio } \\
\text { tradicional } \\
\text { (yacimientos } \\
\text { arqueológicos) }\end{array}$ \\
\hline
\end{tabular}

Las modificaciones realizadas están relacionadas con el apartado actividad que realizan los científicos. Así, mientras que en la rúbrica original se consideraba una concepción alternativano estereotipada en tanto el dibujo represente "(...) actividades realistas que reflejan el trabajo de un científico (...) con las herramientas apropiadas y necesarias" (Farland-Smith 2012 p. 116 [traducción propia]); en la adaptación de la categorización se ha estimado más apropiado considerar como concepciones alternativas-no estereotipadas a aquellos dibujos que representen actividades diferentes a las propias de un laboratorio convencional y aquellos dibujos que representan varios científicos trabajando de forma grupal. Las razones que justifican este cambio son las siguientes: dibujar un científico trabajando en un laboratorio, especialmente realizando experimentos de química, es uno de los estereotipos más comunes encontrados en la literatura, con independencia de si se representan los materiales necesarios para dicha actividad. Además, los elementos dibujados pueden poseer diferentes significados para el participante y para el investigador (Reinisch et al. 2017), por lo que la interpretación de si se han representado las herramientas necesarias resulta muy ambigua. Otro estereotipo común encontrado en la literatura es considerar al científico como una persona solitaria y aislada socialmente. Por ello, parecería más apropiado incluir en la categoría "tradicionalestereotipada" aquellos dibujos que representen a un científico trabajando de forma individual o realizando experimentos propios de un laboratorio convencional (p. ej. Mezclas y disoluciones, uso de probetas y pipetas), y en la categoría "alternativa-no estereotipada" los dibujos que representen científicos trabajando de forma grupal o actividades diferentes a las de laboratorio (p. ej.: redacción de artículos, búsqueda de información, toma de muestra en la naturaleza). Por último, se ha prescindido del sistema de puntuación original según el cual, en función del grado de estereotipia, los dibujos obtenían una puntuación que variaba entre 0 y 9 
puntos totales (Farland-Smith 2012, p. 115-116). Así, cada aspecto de los dibujos es catalogado en cada categoría según las cuatro concepciones descritas anteriormente.

\section{Preguntas escritas}

En esta dimensión, se solicita a los participantes contestar de forma escrita a una serie de preguntas relacionadas con el dibujo, lo que permitiría superar hándicaps de habilidades artísticas y de diferente desarrollo madurativo, y, además, proporciona más información que ayuda a interpretar el dibujo realizado, siendo estos aspectos señalados como importantes limitaciones del DAST (Ehrlén 2009; Reinisch et al. 2017). Las preguntas, situadas en el reverso del folio bajo el epígrafe "Contesta a las siguientes preguntas sobre tu dibujo", son: (I) ¿Quiénes son?; (II) ¿Cómo son?; (III) ¿Dónde trabajan?; (IV) ¿Qué hacen?; y (V) ¿Qué objetos utilizan? Los estudiantes han dispuesto de una hora para la realización del dibujo y de las preguntas escritas.

\section{Prueba de selección de imágenes}

En la tercera dimensión del protocolo propuesto, se emplea una entrevista con fotografías, método útil en la investigación cualitativa con niños (Cappello 2005). La prueba consiste en solicitar a los participantes responder a las preguntas que realiza el entrevistador, seleccionando aquellas (o ninguna) imágenes que representen su respuesta. Para la administración de la prueba, se facilita la siguiente instrucción "Voy a realizarte varias preguntas. Para contestar, debes seleccionar una, más de una, o ninguna de las fotografías que te voy a enseñar. Explica tu elección". A continuación, el investigador realiza una pregunta (tabla 3, segunda columna) y muestra las tres imágenes correspondientes (tabla 3, tercera columna).

Tabla 3. Rúbrica para analizar la prueba de selección de imágenes.

\begin{tabular}{|c|c|c|}
\hline Aspectos & Pregunta & Descripción de las fotografías \\
\hline Apariencia & $\begin{array}{l}\text { ¿Quién hace } \\
\text { ciencia? }\end{array}$ & $\begin{array}{l}\text { 1. Científico loco, varones, realizando experimentos peligrosos. } \\
\text { 2. Científico varón, mediana-avanzada edad, con bata blanca, trabajando } \\
\text { en un laboratorio. } \\
\text { 3. Científica femenina, joven y apariencia normal. }\end{array}$ \\
\hline Origen & ¿Cómo es? & $\begin{array}{l}\text { 1. Figura o persona de apariencia ficticia real, con rasgos de mutaciones } \\
\text { extrañas/robots. } \\
\text { 2. Rasgos caucásicos } \\
\text { 3. Personas negras o extranjeros. }\end{array}$ \\
\hline $\begin{array}{l}\text { Lugar de } \\
\text { trabajo }\end{array}$ & ¿Dónde trabaja? & $\begin{array}{l}\text { 1. Cuevas, sótanos o laboratorios subterráneos y secretos. } \\
\text { 2. Laboratorio convencional, principalmente con elementos de química. } \\
\text { 3. Cualquier lugar real diferente a un laboratorio convencional, como } \\
\text { observatorios o yacimientos arqueológicos. }\end{array}$ \\
\hline Actividad & $\begin{array}{l}\text { ¿Qué hace en su } \\
\text { trabajo? }\end{array}$ & $\begin{array}{l}\text { 1. Experimentos de dudosa moralidad, como bombas, torturas o } \\
\text { pociones. } \\
\text { 2. Actividades propias de un laboratorio de química. } \\
\text { 3. Actividades propias de otras disciplinas científicas: astronomía, } \\
\text { arqueología. }\end{array}$ \\
\hline $\begin{array}{l}\text { Forma de } \\
\text { trabajar }\end{array}$ & ¿Cómo trabaja? & $\begin{array}{l}\text { 1. Aislado socialmente y con rasgos de estar exhausto. } \\
\text { 2. En solitario. } \\
\text { 3. De forma grupal. }\end{array}$ \\
\hline
\end{tabular}

Nota: 1. Fotografía con concepciones sensacionalistas; 2. Fotografía con concepciones tradicionales-estereotipadas; 3. Fotografía con concepciones alternativas-no estereotipadas.

Las imágenes han sido seleccionadas para representar las tres posibles categorías de concepciones de los estudiantes: sensacionalista, que representa motivos y actividades que no son propias del quehacer científico; tradicional-estereotipado, que recoge visiones 
estereotipadas comúnmente identificadas en la literatura; alternativas-no estereotipadas, que representa aspectos no estereotipados sobre los científicos y su trabajo. La inclusión de la prueba de selección de imágenes pretende recabar más información sobre las concepciones de los estudiantes y así determinar con mayor exactitud aquellos aspectos señalados como deficiencias metodológicas del DAST. Más específicamente, en relación con las limitaciones sobre el sexo, apariencia y etnia de los científicos (Losh et al. 2008, Reinisch et al. 2017), en la prueba de imágenes se han incluido fotografías de científicos de ambos sexos (Tabla 3, apariencia), y de rasgos caucásicos, asiáticos y personas negras (Tabla 3, origen). Asimismo, se han incluido imágenes sobre científicos trabajando de forma solitaria y grupal (Tabla 3, forma de trabajar). Además, al permitir al alumnado seleccionar más de una imagen, se supera la limitación relacionada con la coexistencia de más de una concepción en cada participante (Farland-Smith y McComas 2006; Finson et al. 1995), lo que permitiría reducir considerablemente la falta de información derivada del dibujo realizado (Ehrlén 2009; Reinisch et al. 2017). Las elecciones de los estudiantes se evalúan clasificándose en función de las tres posibles concepciones (sensacionalista, tradicional-estereotipada, alternativas-no estereotipadas).

\section{Prueba piloto}

\section{Metodología}

\section{Participantes y procedimiento}

Para estudiar la efectividad del protocolo propuesto con alumnado de diversas capacidades, destrezas y rendimiento académico, se conformó una muestra de conveniencia de diversidad cultural compuesta por un total de 149 estudiantes de $2^{\circ}(n=26), 3^{\circ}(n=13), 4^{\circ}(n=17), 5^{\circ}$ $(n=33)$ y $6^{\circ}(n=60)$ de Educación Primaria. Se han incluido estudiantes españoles $(n=80)$, inmigrantes de segunda generación $(n=41)$ y alumnado español de etnia gitana $(n=28)$. Los estudiantes españoles provenían de un colegio con bajo porcentaje de estudiantes inmigrantes o de etnia gitana situado en una zona de clase media-alta de la ciudad de Burgos (España) Los inmigrantes de segunda generación asistían a una escuela con una muy alta diversidad cultural, también situado en la ciudad de Burgos. La totalidad de los estudiantes de segunda generación habían nacido en España; sin embargo, sus padres provenían de otros países, la mayoría de ellos del este de Europa. Por último, los alumnos españoles de etnia gitana asistían a una escuela segregada en la que la totalidad de los estudiantes eran gitanos, situada en una zona periférica de Valladolid (España).

Para la fase cualitativa, se conformó un segundo muestreo, seleccionando aleatoriamente un número de participantes de la fase cuantitativa. Inicialmente, se pretendía seleccionar un $20 \%$ del número total de participantes, sin embargo, debido a limitaciones de tiempo de los centros educativos, la muestra cualitativa fue menor, con un total de 15 estudiantes $(12,7 \%$ de la muestra total), de los cuales cinco fueron españoles (3 niñas), seis extranjeros de segunda generación ( 2 niñas) y cuatro españoles de etnia gitana (2 niñas). El dibujo y las preguntas escritas se realizaron en una misma sesión para todos los participantes. La prueba de selección de imágenes se desarrolló en el mismo día en el que fue administrado el dibujo y las preguntas escritas en el caso de los estudiantes españoles de etnia gitana, y un día más tarde en el caso de los estudiantes españoles y de los extranjeros de segunda generación.

\section{Análisis}

Para estudiar la efectividad del protocolo propuesto, se han seguido varios procedimientos diferentes de análisis. En primer lugar, para la fase cuantitativa, todos los dibujos fueron 
analizados utilizando la tradicional rúbrica DAST-C (Finson et al. 1995), otorgando un punto por cada estereotipo identificado en el dibujo de cada participante. En segundo lugar, se analizaron nuevamente los dibujos utilizando la categorización propuesta en este estudio, comparando y discutiendo los resultados obtenidos con respecto a la rúbrica DAST-C.

En base a los resultados reportados en la literatura, se han efectuado, para ambas rúbricas, comparaciones según las variables sexo, etnia/procedencia y nivel escolar de los participantes, empleándose pruebas estadísticas no paramétricas debido a la violación de la presunción de distribución de probabilidad normal $(p<.001)$, indicada por la prueba Kolmogorov-Smirnov con corrección de Lilliefors. Además, para determinar la robustez en la utilización de la categorización propuesta se empleó el índice de Kappa para calcular la concordancia interobservador. Para ello, los primeros dos autores de este estudio evaluaron de forma independiente un conjunto de imágenes seleccionadas de forma aleatoria $(n=30)$.

Finalmente, para la fase cualitativa de la prueba piloto, se han analizado las preguntas escritas y la prueba de selección de imágenes, determinando si coincide con el dibujo realizado y discutiendo aquellos aspectos positivos que añade a la interpretación de los mismos.

\section{Resultados y discusión}

\section{Análisis de los dibujos empleando la rúbrica DAST-C}

Los dibujos analizados representaron una imagen generalizada del científico como un varón, especialmente en el caso de los niños, de rasgos caucásicos, que está vestido con una bata y que realiza investigaciones en un laboratorio de forma individual. Estos estereotipos persisten en ambos sexos y en todos los niveles escolares, siendo "trabajo individual", "laboratorio", "investigación" y "varón de rasgos caucásicos" los indicadores estereotipados más representados por los participantes (Tabla 4).

Tabla 4. Porcentaje de participantes que han dibujado los indicadores de la rúbrica

\begin{tabular}{|c|c|c|c|c|c|c|c|c|}
\hline \multicolumn{2}{|c|}{ Indicadores estereotipados } & $\frac{\text { Niños }}{\%}$ & $\frac{\text { Niñas }}{\%}$ & $\begin{array}{c}\mathbf{2}^{\mathbf{o}} \\
\text { E.P. } \\
\%\end{array}$ & $\begin{array}{c}\mathbf{3}^{\mathbf{o}} \\
\text { E.P. } \\
\%\end{array}$ & $\begin{array}{c}4^{\mathbf{o}} \\
\text { E.P. } \\
\%\end{array}$ & \multirow{2}{*}{$\begin{array}{c}\mathbf{5}^{\mathbf{0}} \\
\text { E.P. } \\
\%\end{array}$} & \multirow{2}{*}{$\begin{array}{c}\mathbf{6}^{\mathbf{0}} \\
\text { E.P. } \\
\% \\
\end{array}$} \\
\hline & & & & & & & & \\
\hline \multirow[t]{8}{*}{ Apariencia } & Creatura mística & 16.7 & 8.2 & 11.8 & 18.2 & 0 & 18.8 & 12.3 \\
\hline & Bata laboratorio & 56.9 & 65.6 & 52.9 & 54.5 & 62.5 & 65.6 & 61.4 \\
\hline & Gafas & 44.4 & 41.0 & 23.5 & 36.4 & 62.5 & 34.4 & 49.1 \\
\hline & Vello facial & 4.2 & 0 & 5.9 & 0.0 & 0 & 3.1 & 1.8 \\
\hline & Varón & 88.9 & 45.9 & 47.1 & 81.8 & 68.8 & 62.5 & 77.2 \\
\hline & Caucásico & 83.3 & 100.0 & 100.0 & 90.9 & 75.0 & 93.8 & 91.2 \\
\hline & Edad avanzada & 16.7 & 18.0 & 5.9 & 18.2 & 18.8 & 9.4 & 24.6 \\
\hline & Loco-enfadado & 25.0 & 14.8 & 0.0 & 36.4 & 18.8 & 34.4 & 15.8 \\
\hline \multirow[t]{6}{*}{ Actividad } & Investigación & 88.9 & 90.2 & 76.5 & 72.7 & 87.5 & 96.9 & 93.0 \\
\hline & Conocimiento & 22.2 & 23.0 & 5.9 & 27.3 & 25.0 & 31.3 & 21.1 \\
\hline & Productos & 22.2 & 11.5 & 41.2 & 45.5 & 18.8 & 12.5 & 7.0 \\
\hline & Expresiones & 16.7 & 18.0 & 23.5 & 45.5 & 6.3 & 6.3 & 19.3 \\
\hline & Símbolos peligro & 15.3 & 9.8 & 11.8 & 9.1 & 0.0 & 15.6 & 15.8 \\
\hline & Individual & 88.9 & 86.9 & 94.1 & 72.7 & 81.3 & 90.6 & 89.5 \\
\hline \multirow{4}{*}{$\begin{array}{l}\text { Lugar de } \\
\text { trabajo }\end{array}$} & Secreto & 0.0 & 1.6 & 0.0 & 0.0 & 6.3 & 3.1 & 0.0 \\
\hline & Laboratorio & 80.6 & 90.2 & 64.7 & 81.8 & 87.5 & 84.4 & 91.2 \\
\hline & Clandestino & 2.8 & 4.9 & 17.6 & 9.1 & 0.0 & 0.0 & 1.8 \\
\hline & Bombillas & 6.9 & 6.6 & 5.9 & 9.1 & 6.3 & 6.3 & 7.0 \\
\hline
\end{tabular}

En cuanto a la variable sexo, el estadístico U de Mann-Whitney reveló que no hay diferencias significativas en el número total de indicadores estereotipados dibujados por los niños y las niñas, $\mathrm{U}=1811.500, z=-.902, p=.367, r=.08$. No obstante, atendiendo a la tipología de los 
indicadores, se obtuvo que las niñas han dibujado significativamente más estereotipos relacionados con el lugar de trabajo de los científicos en comparación con los niños, $\mathrm{U}=$ 1674.500, $z=-2.317, \mathrm{p}=.02, r=.20$. La figura 1 muestra el número medio de estereotipos dibujados por las niñas y los niños.

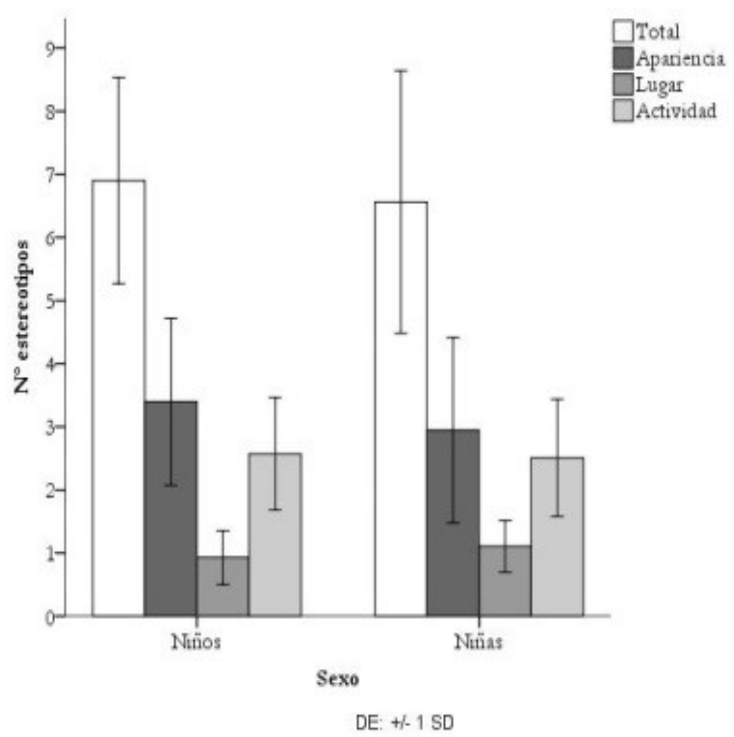

Figura 1. Número medio de estereotipos dibujados según el sexo de los estudiantes

El estadístico Kruskal-Wallis reveló que no hay diferencias significativas en el número total de indicadores estereotipados dibujados por los estudiantes españoles, extranjeros de segunda generación y españoles de etnia gitana, $\chi^{2}(2, n=127)=1.920, p=.383$. Sin embargo, atendiendo a los estereotipos según su tipología, se registró que los estudiantes de etnia gitana han dibujado un mayor número de estereotipos relacionados con el lugar de trabajo de los científicos que los estudiantes extranjeros y que los españoles, $\chi^{2}(2, n=127)=6.714, p=$. 035. La figura 2 muestra el número medio de estereotipos dibujados según el nivel escolar.

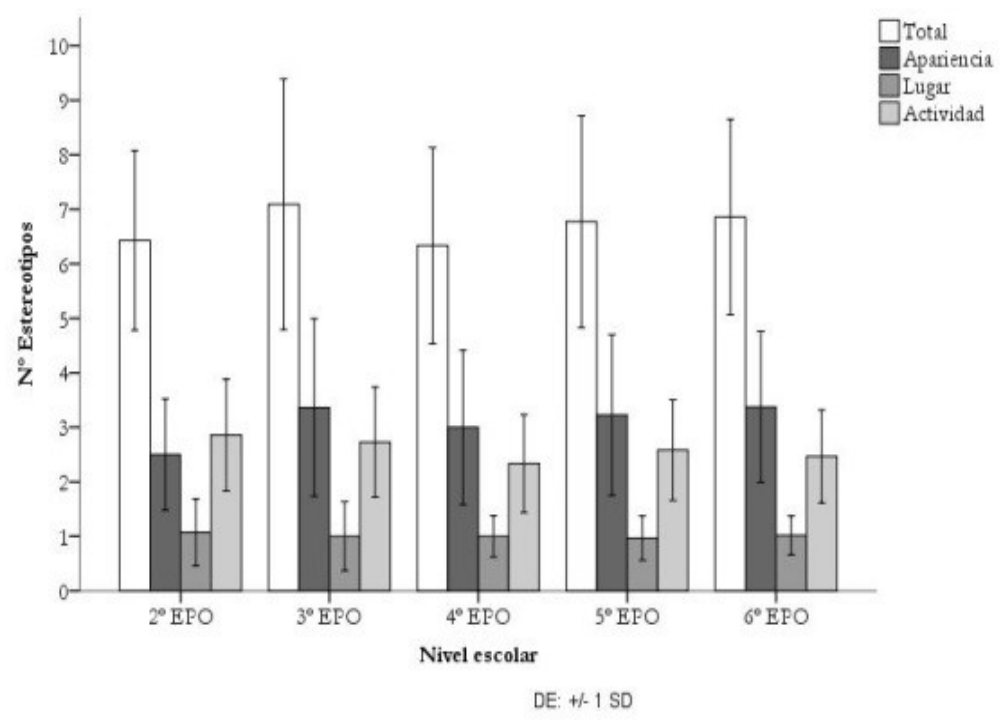

Figura 2. Número medio de estereotipos dibujados según el nivel escolar de los estudiantes

Asimismo, en relación con el nivel escolar, el estadístico Kruskal-Wallis reveló que tampoco hay diferencias significativas en el número total de indicadores estereotipados dibujados, $\chi^{2}$ (4, $n=127)=1.386, p=.847$. Tampoco se encontraron diferencias significativas en las dimensiones apariencia de los cientificos, $\chi^{2}(4, n=127)=4.679, p=.322$, lugar de trabajo $\chi^{2}(4, n=$ 
$127)=.629, p=.960$, ni en la actividad que realizan $\chi^{2}(4, n=127)=3.463, p=.484$. La figura 1 muestra el número medio de estereotipos dibujados por los estudiantes españoles, extranjeros de segunda generación y españoles de etnia gitana.

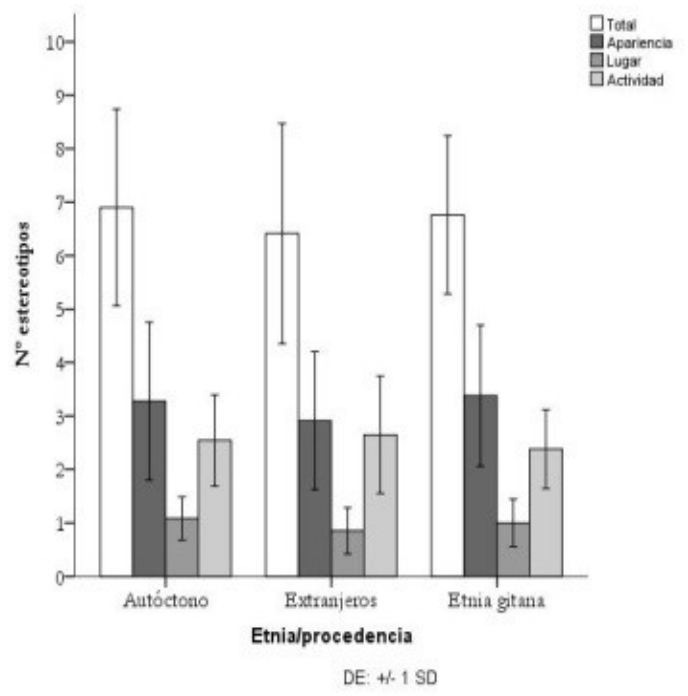

Figura 3. Número medio de estereotipos dibujados según los antecedentes culturales de los estudiantes

\section{Análisis de los dibujos empleando la rúbrica modificada}

En general, los dibujos de los estudiantes han mostrado concepciones estereotipadas sobre los científicos. Así, un 57,1\% de los dibujos han plasmado concepciones estereotipadas y sensacionalistas sobre la apariencia de los científicos, un $68.5 \%$ sobre el trabajo que realizan, y finalmente un $81,9 \%$ sobre el lugar en el que desempeñan su labor. Más específicamente, la mayoría de los dibujos han representado científicos varones, de rasgos caucásicos, con bata de laboratorio y mediana-avanzada edad, trabajando de forma individual en un laboratorio convencional realizando actividades propias de laboratorio, como experimentos químicos. La apariencia de los cientificos ha sido la categoría que ha registrado un mayor número de concepciones alternativas-no estereotipadas (32.9\%). Por el contrario, la actividad de los cientificos ha sido la categoría con un mayor número de dibujos que muestran imágenes sensacionalistas (21.5\%). Estos resultados se desglosan a continuación y se recogen en las tablas 5, 6 y 7.

Para la apariencia de los científicos (Tabla 5), el test de independencia de Chi-cuadrado reveló la existencia de diferencias significativas en la distribución de los participantes en las cuatro categorías de concepciones sobre los científicos para la variable sexo, $\chi^{2}(3, n=149)=13.117$, $p=.004, \mathrm{y}$ nivel escolar, $\chi^{2}(12, n=149)=47.881, p<.001$. Atendiendo a la variable etnia/procedencia de los estudiantes, no se identificaron diferencias significativas en su distribución $\chi^{2}(6, n=149)=8.844, p=.183$. Así, en la categoría tradicional-estereotipada, predominaron los dibujos realizados por los niños (65\%), y, por el contrario, han sido las niñas las que han plasmado un mayor número de dibujos categorizados como alternativos-no estereotipados (67.3\%), representando minorías étnicas, extranjeros y/o mujeres en lugar de hombres caucásicos o caricaturas/científicos locos. Además, los estudiantes de niveles superiores han sido mayoría en la categoría sensacionalista $(52 \%)$ y tradicional-estereotipada $(51.7 \%)$ que los de niveles inferiores, especialmente en comparación con los de $2^{\circ}$ de Educación Primaria, con apenas un $12 \%$ y $3.3 \%$ de dibujos categorizados como sensacionalistas y tradicionales-estereotipados, respectivamente. 
Tabla 5. Categorización de los dibujos según la apariencia de los científicos

\begin{tabular}{|c|c|c|c|c|}
\hline & $\begin{array}{c}\text { Sin determinar } \\
(\%)\end{array}$ & $\begin{array}{c}\text { Sensacionalista } \\
(\%)\end{array}$ & $\begin{array}{c}\text { Tradicional } \\
\text { estereotipada } \\
(\%) \\
\end{array}$ & $\begin{array}{c}\text { Alternativa } \\
\text { no estereotipada } \\
(\%)\end{array}$ \\
\hline Niñas & 40 & 36 & 35 & 67.3 \\
\hline Niños & 60 & 64 & 65 & 32.7 \\
\hline $2^{\circ}$ E.P. & 66.7 & 12 & 3.3 & 22.4 \\
\hline $3^{\circ}$ E.P. & 6.7 & 8 & 13.3 & 4.1 \\
\hline $4^{\circ}$ E.P. & 6.7 & 0 & 15 & 14.3 \\
\hline $5^{\circ}$ E.P. & 0 & 28 & 16.7 & 30.6 \\
\hline $6^{\circ}$ E.P. & 20 & 52 & 51.7 & 28.6 \\
\hline Españoles & 40 & 76 & 48.3 & 53.1 \\
\hline Extranjeros & 33.3 & 20 & 7 & 30.6 \\
\hline Etnia gitana & 26.7 & 4 & 0 & 16.3 \\
\hline Total & $n=15(10)$ & $n=25(16.8)$ & $n=60(40,3)$ & $n=49(32.9)$ \\
\hline
\end{tabular}

Para la actividad que realizan los científicos (Tabla 6), el test de independencia de Chi-cuadrado reveló la existencia de diferencias significativas en la distribución de los participantes en las cuatro categorías de concepciones sobre los científicos para la variable nivel escolar, $\chi^{2}(12, n$ $=149)=47.622, p<.001$. No se encontraron diferencias según la variable sexo, $\chi^{2}(3, n=$ $149)=.747, p=.862$, ni tampoco según la variable etnia/procedencia de los estudiantes, $\chi^{2}$ (6, $n=149)=8.503, p=.204$. Más específicamente, en las categorías sensacionalistas $\mathrm{y}$ tradicionales-estereotipadas han predominado dibujos de estudiantes de niveles escolares superiores. En otras palabras, los estudiantes de niveles superiores (50\%) conciben la actividad de los científicos de una forma más estereotipada que los de niveles inferiores $(2.9 \%)$. No obstante, también son los estudiantes de niveles superiores quienes poseen visiones más alternativas-no estereotipadas sobre las actividades que realizan los científicos, con casi la mitad $(46.2 \%)$ de los dibujos categorizados como alternativos-no estereotipados perteneciendo al $6^{\circ}$ nivel de EP. Si bien no se han registrado diferencias significativas según la etnia/procedencia de los estudiantes, la mayoría de dibujos de la categoría alternativa-no estereotipada para la actividad representada han sido realizados por estudiantes españoles $(57.7 \%)$ y extranjeros (38.5). Sin embargo, también han sido los españoles quienes han dibujado un mayor número de dibujos sensacionalistas $(62.5 \%)$.

Tabla 6. Categorización de los dibujos según la actividad que realizan los científicos

\begin{tabular}{|c|c|c|c|c|}
\hline & $\begin{array}{c}\text { Sin determinar } \\
(\%)\end{array}$ & $\begin{array}{c}\text { Sensacionalista } \\
(\%) \\
\end{array}$ & $\begin{array}{c}\text { Tradicional } \\
\text { estereotipada } \\
(\%) \\
\end{array}$ & $\begin{array}{c}\text { Alternativa } \\
\text { no estereotipada } \\
(\%)\end{array}$ \\
\hline Niñas & 52.4 & 40.6 & 47.1 & 46.2 \\
\hline Niños & 47.6 & 59.4 & 52.9 & 53.8 \\
\hline $2^{\circ}$ E.P. & 47.1 & 21.9 & 2.9 & 19.2 \\
\hline $3^{\circ}$ E.P. & 9.5 & 15.6 & 5.7 & 7.7 \\
\hline $4^{\circ}$ E.P. & 9.5 & 0 & 20 & 3.8 \\
\hline $5^{\circ}$ E.P. & 9.5 & 28.1 & 21.5 & 23.1 \\
\hline $6^{\circ}$ E.P. & 14.3 & 34.4 & 50 & 46.2 \\
\hline Españoles & 42.9 & 62.5 & 51.4 & 57.7 \\
\hline Extranjeros & 28.6 & 25 & 24.3 & 38.5 \\
\hline Etnia gitana & 28.6 & 12.5 & 24.3 & 3.8 \\
\hline Total & $n=21(14.1)$ & $n=32(21.5)$ & $n=70(47)$ & $n=26(17.4)$ \\
\hline
\end{tabular}


estereotipada, alternativa-no estereotipada) y para cada variable (sexo, nivel escolar, etnia/procedencia)

Para la dimensión lugar de trabajo de los científicos (Tabla 7), el test de independencia de Chicuadrado reveló la existencia de diferencias significativas en la distribución de los participantes en las cuatro categorías de concepciones sobre los científicos para la variable nivel escolar, $\chi^{2}$ $(12, n=149)=46.167, p<.001$. No se encontraron diferencias según la variable sexo, $\chi^{2}(3, n$ $=149)=.469, p=.926$, ni tampoco según la variable etnia/procedencia, $\chi^{2}(6, n=149)=$ $6.187, p=.403$. Por tanto, los estudiantes de niveles superiores son quienes asimismo conciben el lugar de trabajo de los científicos de una forma más estereotipada en comparación con los de niveles inferiores. Así, casi la mitad de los dibujos (48.5\%) que han representado laboratorios de ciencia convencionales pertenecen a estudiantes de $6^{\circ}$ nivel. Por otro lado, los estudiantes de niveles inferiores son los que más dibujos sensacionalistas han dibujado (66.7\%), representando cuevas, sótanos o lugares secretos. En línea con la actividad que realizan los científicos, han sido los estudiantes españoles quienes han mostrado una visión más estereotipada sobre los lugares de trabajo de los científicos, con un $66.7 \%$ y $57.4 \%$ de los dibujos sensacionalistas y tradicionales-estereotipados dibujados por ellos.

Tabla 7. Categorización de los dibujos según el lugar de trabajo de los científicos.

\begin{tabular}{|c|c|c|c|c|}
\hline & $\begin{array}{c}\text { Sin determinar } \\
(\%)\end{array}$ & $\begin{array}{c}\text { Sensacionalista } \\
(\%)\end{array}$ & $\begin{array}{c}\text { Tradicional } \\
\text { estereotipada } \\
(\%)\end{array}$ & $\begin{array}{c}\text { Alternativa } \\
\text { no estereotipada } \\
(\%)\end{array}$ \\
\hline Niñas & 52.4 & 50 & 45.5 & 42.9 \\
\hline Niños & 47.6 & 50 & 54.5 & 57.1 \\
\hline $2^{\circ}$ E.P. & 57.1 & 66.7 & 5.9 & 19 \\
\hline $3^{\circ}$ E.P. & 9.5 & 0 & 7.9 & 14.3 \\
\hline $4^{\circ}$ E.P. & 9.5 & 0 & 13.9 & 4.8 \\
\hline $5^{\circ}$ E.P. & 9.5 & 16.7 & 23.8 & 23.8 \\
\hline $6^{\circ}$ E.P. & 14.3 & 16.7 & 48.5 & 38.1 \\
\hline Españoles & 42.9 & 66.7 & 57.4 & 42.9 \\
\hline Extranjeros & 28.6 & 33.3 & 23.8 & 42.9 \\
\hline Etnia gitana & 28.6 & 0 & 18.8 & 14.3 \\
\hline Total & $n=21(14.1)$ & $n=6(4)$ & $n=101(67.8)$ & $n=21(14.1)$ \\
\hline
\end{tabular}

En conjunto, los resultados de la rúbrica propuesta contradicen y complementan algunos datos obtenidos utilizando la rúbrica DAST-C. De este modo, mientras que utilizando la rúbrica DAST-C se ha obtenido que las niñas poseen una visión más estereotipada sobre el lugar de trabajo de los científicos en comparación con los niños, los resultados de la dimensión representativa no soportan estas evidencias, sugiriendo que tanto niñas como niños conciben el lugar de trabajo de los cientificos de manera similar. También se han identificado discrepancias entre las dos rúbricas en cuanto a las variables nivel escolar y etnia/procedencia de los estudiantes. Según la rúbrica DAST-C, los estudiantes de todos los niveles escolares poseen concepciones similares, siendo los de etnia gitana los que conciben de forma más estereotipada el lugar de trabajo de los científicos. Estos resultados no coinciden con los obtenidos empleando la nueva rúbrica propuesta, que muestra, por un lado, que los estudiantes de niveles superiores conciben de forma más estereotipada tanto la apariencia de los científicos, la actividad que realizan, así como el lugar de trabajo. Además, empleando la nueva rúbrica propuesta no se han encontrado diferencias entre las concepciones de los estudiantes españoles, de etnia gitana y de los extranjeros.

Por otro lado, las modificaciones realizadas a la rúbrica han permitido establecer nuevas diferencias entre las concepciones de los estudiantes. A diferencia de la rúbrica DAST-C, la dimensión representativa ha señalado diferencias significativas en las concepciones de los 
estudiantes sobre la apariencia de los científicos, siendo los niños los que han realizado un mayor número de dibujos sensacionalistas (64\%) y tradicionales estereotipados (65\%). Además, la rúbrica DAST-C no ha encontrado diferencias según el nivel escolar en ninguna de las dimensiones de los dibujos, sin embargo, la nueva rúbrica propuesta ha permitido identificar que a medida que aumenta el nivel escolar también aumentan las imágenes estereotipadas sobre los científicos, tanto en relación su apariencia, como sobre la actividad que realizan y el lugar en el que desempeñan su trabajo.

En cuanto a la categorización de los dibujos siguiendo la rúbrica propuesta, el índice de Kappa mostró un índice alto de concordancia inter-observador $(k=.85)$ (Landis y Koch 1977), sugiriendo que la categorización de los dibujos empleando la rúbrica propuesta es fiable.

\section{Preguntas escritas y prueba de selección de imágenes}

En este apartado, se recogen los resultados obtenidos durante la fase cualitativa que respaldan el uso de la nueva rúbrica. Además, se ejemplifican las ventajas que reporta la adición de preguntas escritas y una prueba de selección de imágenes para superar algunas de las principales limitaciones reportadas en la literatura relacionada con el uso del DAST. Estas ventajas son:

- Aportan nueva información que ha sido imposible de determinar a partir del dibujo

En la fase cuantitativa se han identificado dibujos que presentaban habilidades artísticas dispares (Losh et al. 2008, Reinisch et al. 2017) o que presentaban información limitada o confusa (Ehrlén, 2009; Reinisch et al. 2017). Así, la figura 4 representa una visión tradicionalestereotipada de la apariencia de los científicos, sin embargo, no incluye suficiente información para determinar el trabajo que realiza el científico ni el lugar en el que lo realiza. Tanto las preguntas escritas como la prueba de selección de imágenes han ayudado a suplir esta falta de información, identificando que el estudiante posee asimismo una concepción tradicionalestereotipada sobre el lugar de trabajo y la tarea que realiza. Así, el estudiante ha escrito que "(...) trabaja en un laboratorio utilizando máquinas bien grandes y haciendo experimentos guais", y ha seleccionado la segunda imagen, que representa visiones tradicionales-estereotipadas, de cada uno de los apartados de la prueba de selección de imágenes (ver tabla 3).

Otros ejemplos de dibujos con información limitada o confusa son las figuras 5 y 6 . Si bien en la figura 5 se identifica una concepción tradicional-estereotipada del lugar de trabajo, no se puede saber con certeza si la concepción de su apariencia y actividad que realiza es sensacionalista o tradicional-estereotipada, y el sexo del científico dibujado resulta ambiguo, siendo esta otra de las principales críticas recurrentes con el uso del DAST (Losh et al. 2008; Reinisch et al. 2017). Las respuestas de la estudiante ayudaron a clarificar que se trata de un varón y de una concepción sensacionalista, dado que ha argumentado que "Es un científico loco y viejo. Tiene el pelo gris y los ojos negros. A veces es muy torpe y se lía con los componentes. Trabaja en un laboratorio utilizando componentes peligrosos." La prueba de selección de imágenes ha ayudado a confirmar la concepción tradicional-estereotipada sobre el lugar de trabajo (seleccionando la imagen que representa un laboratorio) y la concepción sensacionalista sobre la actividad que realiza, puesto que ha seleccionado la imagen que representa experimentos de dudosa moralidad, como pócimas, y la primera imagen que representa a un científico con rasgos de estar cansado trabajando de manera aislada socialmente. No obstante, en relación con la apariencia, la alumna ha seleccionado las primeras dos fotografías que representan, por un lado, un científico varón realizando experimentos peligrosos, y por otro, un científico varón, de mediana-avanzada edad, con bata blanca, trabajando en un laboratorio (ver tabla 3), lo que parece sugerir la coexistencia de más de una imagen sobre los científicos que no ha podido ser plasmada mediante un solo dibujo (Farland-Smith y McComas, 2006; Finson et al. 
1995).

La figura 6 representa una situación similar. Las preguntas escritas ayudaron a confirmar que la alumna posee una visión sensacionalista sobre la apariencia de los científicos y a determinar una visión sensacionalista sobre el trabajo que realizan y una visión tradicional-estereotipada sobre el lugar de trabajo, argumentando que "Es feo, bajo y loco. Sabe hacer pociones. Utiliza probetas y otros artilugios que están en el laboratorio". En cuanto a la prueba de selección de imágenes, permitió confirmar la visión sobre el trabajo que realiza y el lugar de trabajo. No obstante, la alumna argumentó que los científicos trabajan tanto de forma individual como en grupo, lo que sugiere una visión alternativa-no estereotipada sobra la forma de trabajar de los cientificos.

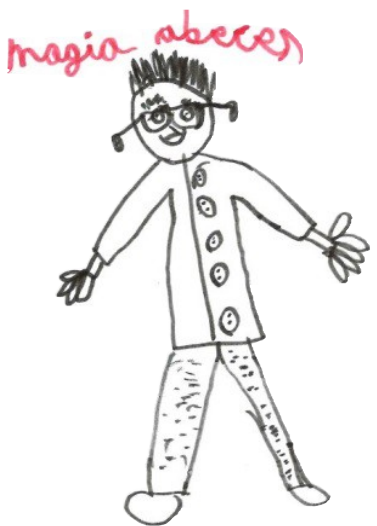

Figura 4. Niño etnia gitana, $3^{\circ}$ E.P.

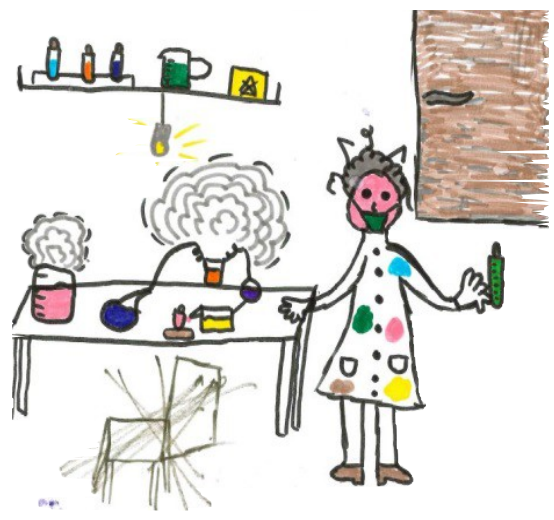

Figura 5. Niña española, $5^{\circ}$ E.P.

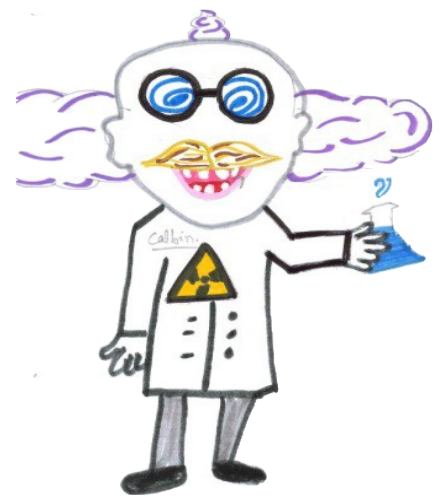

Figura 6. Niña extranjera, $6^{\circ}$ E.P.

- Aclaran detalles del dibujo

Además de los ejemplos anteriores, en ocasiones, no se puede interpretar la etnia o la nacionalidad de los científicos dibujados (Reinisch et al. 2017), siendo este el caso de la figura 7 , en la que no resulta claro si el estudiante ha coloreado a la persona dibujada para representar su etnia o nacionalidad. La prueba de selección de imágenes ha permitido arrojar más luz a este aspecto, sugiriendo que el estudiante posee una visión tradicional-estereotipada sobre la apariencia del científico al haber seleccionado la imagen de un hombre caucásico (pregunta 1) y de rasgos occidentales (pregunta 2). Además, el estudiante no ha aportado más información en las preguntas escritas sobre la nacionalidad o etnia del científico dibujado, lo que parecería sugerir que el participante no posee concepciones alternativas sobre quién hace ciencia, sino que ha coloreado al científico por costumbre o por ser una práctica común, al igual que los estudiantes que realizaron los dibujos de las figuras 5 y 8 .

Otra limitación está relacionada con representar a los científicos trabajando de forma solitaria. Investigaciones pasadas han mostrado que esto podría deberse más a la falta de tiempo o de habilidad artística (Reinisch et al. 2017), y no tanto por considerar que los científicos son personas solitarias. Por ejemplo, en la figura 6 , se ha representado a un solo científico, sin embargo, en la prueba de selección de imágenes la estudiante ha seleccionado también la fotografía que muestra a los científicos trabajando en grupo, argumentando que al su trabajo requiere realizar cosas complicadas, por lo que necesitan ayuda. Si bien las modificaciones realizadas en este estudio con respecto al protocolo DAST no ha solventado esta limitación, sí han permitido identificar la posible coexistencia de más de una concepción sobre la forma en que trabajan los científicos, permitiendo a los estudiantes más oportunidades para compartir sus concepciones, algo que no sucede con la rúbrica DAST original según la cual la forma de trabajar de la científica representada en la figura 6 sería solitaria, concibiéndose que el 
estudiante posee una visión estereotipada sobre la manera de trabajar de los científicos.

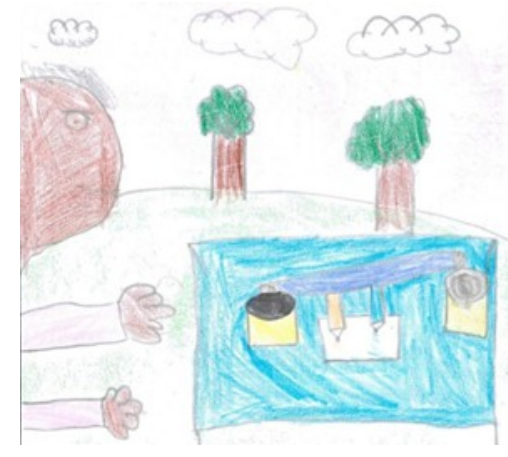

Figura 7. Niño extranjero, $4^{\circ}$ E.P.

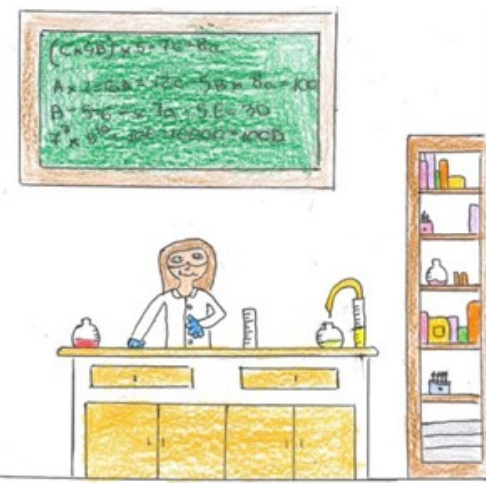

Figura 8. Niña española, $6^{\circ}$ E. P.

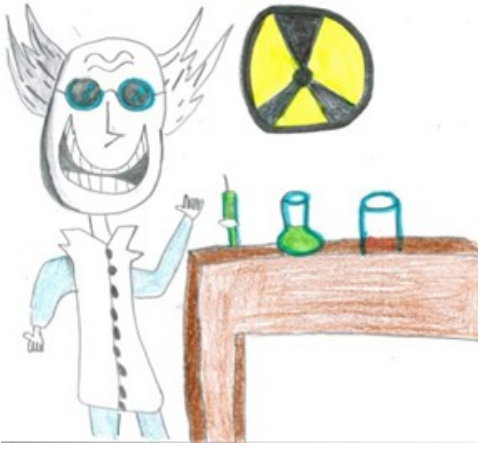

Figura 9. Niño español, $6^{\circ}$ E.P.

- Aporta más información acerca de imágenes socialmente reconocibles

Finson y Pederson (2011) argumentaron que los estudiantes podrían estar plasmando determinados estereotipos ligados a los científicos con el fin de que su dibujo sea socialmente reconocible. Las preguntas escritas y la prueba de selección de imágenes muestran que la figura 9 es un ejemplo de ello. Así, mientras que el estudiante ha representado concepciones sensacionalistas sobre la apariencia y el trabajo de los científicos, en la dimensión escrita ha justificado que "Tienen muchos estudios. Pueden tener algunos defectos de cualquier tipo. Como todo el mundo. Nadie es perfecto” y, además, en la prueba de selección de imágenes ha seleccionado las fotografías que muestran visiones tradicionales-estereotipadas y alternativas en los apartados “¿Quién hace ciencia?”, “¿Qué hace en su trabajo?” y “¿Cómo trabaja?” (ver tabla 3), lo que muestra que su concepción de los científicos es menos estereotipada de lo que plasmó en su dibujo. Así, la inclusión de preguntas escritas y de la prueba de selección de imágenes no solo ha puesto de relieve las limitaciones del protocolo DAST original, sino que además ha permitido que la categorización del dibujo se realice de una forma más objetiva y con mayor precaución.

- Aporta información acerca de aspectos psicológicos de los científicos

Además de concepciones relacionadas con la apariencia o el trabajo de los científicos, los estudiantes poseen creencias sobre la ciencia o el que hacer de los científicos como una carrera difícil de alcanzar y solo destinada para personas muy inteligentes. Por tanto, parecería que los factores psicológicos asociados a la ciencia y a los científicos podrían estar frenando las aspiraciones a seguir una carrera en ciencias (DeWitt y Archer 2015). Así, parecería necesario que un protocolo que aspira a diagnosticar las concepciones que poseen los estudiantes sobre los científicos sea capaz de identificar también aspectos psicológicos sobre los mismos. De este modo, la inclusión de las preguntas escritas ha permitido identificar que estas concepciones relacionadas con componentes psicológicos de los científicos están presentes desde niveles elementales del sistema educativo. A continuación, se recogen algunos extractos que aluden a la capacidad brillante de los científicos o a su inteligencia:

"Es muy listo (...)". Niño de etnia gitana de $6^{\circ}$ de Educación Primaria.

"Suelen ser alto [sic], esbeltos, inteligentes, muy estudiosos, experimentadores. Son muy majos y hablan de cosas interesantes. No tienen ningún defecto.” Niño extranjero de $6^{\circ}$ de Educación Primaria.

“Tienen muchos estudios”. Niño español de $6^{\circ}$ de Educación Primaria.

“Es muy listo.” Niña española de 5 de Educación Primaria.

"Joven, guapa y lista. Siempre aprovecha el tiempo y le encanta hacer experimentos con colores." Niña española de $6^{\circ}$ de Educación Primaria. 


\section{Conclusiones}

En este trabajo se han detallado las modificaciones realizadas al protocolo DAST y se han reportado los resultados obtenidos en un estudio piloto. En general, los resultados sugieren que los cambios propuestos son efectivos en la identificación y análisis de las percepciones e imágenes de los estudiantes acerca de los científicos, reduciendo algunos de los problemas metodológicos identificados en el uso del DAST. La prueba piloto realizada con estudiantes de Educación Primaria de diversidad cultural parece indicar que estos cambios permiten avanzar hacia el desarrollo de un protocolo más fiable y exacto en la identificación de las concepciones que poseen los estudiantes sobre los científicos, aunque aún hay aspectos que necesitan de futuros estudios.

De este modo, en primer lugar, la modificación de la rúbrica de evaluación de los dibujos ha permitido registrar más diferencias entre las concepciones de los participantes de diferente edad y etnia o antecedentes culturales gracias a una evaluación más holística de lo representado y no a la mera cuantificación del número de estereotipos plasmados, permitiendo asimismo superar los problemas derivados de habilidades artísticas dispares entre los estudiantes. Además, la estandarización de su administración y de las instrucciones facilitadas a los estudiantes ha permitido disminuir los problemas identificados en la literatura con la falta de material o tiempo para plasmar las propias concepciones.

En segundo lugar, la utilización de la nueva rúbrica ha mostrado ser robusta, obteniéndose una gran coincidencia entre las categorizaciones realizadas a una muestra de dibujos de forma independiente por dos investigadores diferentes, lo que sugiere que los resultados obtenidos de su uso poseen un alto grado de fiabilidad.

Finalmente, la adición de las preguntas escritas y de la prueba de selección de imágenes ha confirmado los resultados obtenidos mediante la nueva rúbrica, y, además, ha complementado algunas de las interpretaciones. De este modo, se han disminuido algunos problemas metodológicos de versiones anteriores del DAST, consiguiendo (I) añadir más información sobre las concepciones de los estudiantes que no han podido ser determinadas a partir del dibujo, como por ejemplo el sexo y la etnia o nacionalidad de los científicos dibujados, (II) aclarar aspectos confusos del dibujo, como por ejemplo el material que utilizan o el lugar en el que trabajan, y (III) aportando información sobre las concepciones que poseen los estudiantes acerca de los factores psicológicos de los científicos y no solo sobre su apariencia o quehacer científico.

Pese a todo lo anterior, las mejoras propuestas en este estudio no están exentas de limitaciones. Si bien se ha intentado reducir en todo lo posible el sesgo introducido por las instrucciones de administración de los dibujos, la frase empleada ("Imagina que vas de viaje a ver como se hace ciencia. Dibuja quién hace ciencia, cómo es, dónde trabaja y qué hace") podría implícitamente inducir al estudiante a dibujar una sola persona. La prueba de selección de imágenes parece soportar esta presunción, dado que la mayoría de estudiantes han seleccionado la imagen que representa a científicos trabajando de forma grupal, pese a haber dibujado a un solo científico. Por tanto, se trata de un aspecto que requiere de futuros estudios. Otro aspecto está relacionado con las preguntas escritas. Mientras que estas han permitido acceder a las concepciones que poseen los estudiantes sobre las características psicológicas de los científicos, esto se ha dado de forma implícita. Por consiguiente, parecería necesario desarrollar en futuros estudios procedimientos que soliciten de forma explícita información acerca de estos factores tan importantes en el desarrollo de las vocaciones científicas de los estudiantes. Por último, la muestra empleada para la fase cualitativa del estudio ha sido muy irregular en términos de edad de los participantes. Si bien el objetivo 
principal de este estudio consistió en probar un nuevo protocolo basado en el DAST y no diagnosticar en sí las imágenes que poseen los estudiantes sobre los científicos, la baja muestra de alumnado ha limitado las conclusiones que podrían extraerse de la fase cualitativa. A este respecto, convendría realizar futuros estudios en los que se conforme una muestra cualitativa más amplia y regular, seleccionando un número similar de participantes de cada categoría de concepciones (sensacionalista, tradicional-estereotipada y alternativa-no estereotipada), lo que permitiría caracterizar mejor las diferencias y similitudes entre los estudiantes en cuanto a variables de edad, sexo y etnia o nacionalidad.

En definitiva, en este trabajo se avanza en el desarrollo de protocolos más fiables para la identificación de imágenes sobre los científicos. Las modificaciones realizadas al protocolo DAST original redujo algunas de las deficiencias metodológicas reportadas en la literatura y permitió acceder de una forma más holística y fiable a las concepciones de los estudiantes. La inclusión de preguntas escritas y la prueba de selección de imágenes parecerían ser críticas pues revelaron las concepciones subyacentes que no han podido ser identificadas a partir de los dibujos, lo que ayuda a definir mejor los significados de algunas imágenes ambiguas y a confirmar el significando de otros aspectos plasmados en los dibujos.

\section{Agradecimientos}

Queremos agradecer al editor y a los dos revisores anónimos por sus comentarios y sugerencias que han contribuido a mejorar sustancialmente este trabajo. Asimismo, agradecemos especialmente la colaboración de los centros escolares y estudiantes implicados en este estudio.

\section{Referencias}

Andersen, H. M., Krogh, L. B., Lykkegaard, E. (2014) Identity Matching to Scientists: Differences that Make a Difference? Research in Science Education, 44(3), 439-460. doi: 10.1007/s11165-013-9391-9

Boyd, D., Bee, H. (2006) Lifespan development. Boston, MA: Pearson.

Cappello, M. (2005) Photo Interviews: Eliciting Data through Conversations with Children. Field Methods, 17(2), 170-182. doi:10.1177/1525822X05274553

Chambers, D. W. (1983) Stereotypic images of the scientist: The draw-a-scientist test. Science Education, 67(2), 255-265. doi:10.1002/sce.3730670213

DeWitt, J., Archer, L. (2015) Who Aspires to a Science Career? A comparison of survey responses from primary and secondary school students. International Journal of Science Education, 37(13), 2170-2192. doi:10.1080/09500693.2015.1071899

DeWitt, J., Archer, L., Osborne, J. (2013) Nerdy, Brainy and Normal: Children's and Parents' Constructions of Those Who Are Highly Engaged with Science. Research in Science Education, 43(4), 1455-1476. doi:10.1007/s11165-012-9315-0

Ehrlen, K. (2009) Drawings as representations of children's conceptions. International Journal of Science Education, 31(1), 41-57. doi:10.1080/09500690701630455

Farland-Smith, D. (2009) How Does Culture Shape Students' Perceptions of Scientists? CrossNational Comparative How Does Culture Shape Students' Perceptions of Scientists? Cross- National Comparative Study of American and Chinese Elementary Students. Journal of Elementary Science Education, 21(4), 23-42. doi:10.1007/BF03182355

Farland-Smith, D. (2012) Development and field test of the modified Draw-a-Scientist Test and the Draw-a-Scientist Rubric. School Science and Mathematics, 112(2), 109-116. 
doi:10.1111/j.1949-8594.2011.00124.x

Farland-Smith, D., McComas, W. F. (2006) Deconstructing the DAST: Development of a valid and reliable tool for assessing students' perceptions of scientists. En Association of Science Teacher Educator Conference. Clearwater, FL.

Finson, K. D. (2002) Drawing a Scientist: What We Do and Do Not Know After Fifty Years of Drawings. School Science and Mathematics, 102(7), 335-345. doi:10.1111/j.19498594.2002.tb18217.x

Finson, K. D., Beaver, J. B., Cramond, B. L. (1995) Development and field test of a checklist for the draw-a-scientist test. School Science and Mathematics, 95(4), 195-205. doi:10.1111/j.1949-8594.1995.tb15762.x

Finson, K., Pederson, J. (2011) What are Visual Data and What Utility do they have in Science Education? Journal of Visual Literacy, 30(1), 66-85. doi:10.1080/23796529.2011.11674685

Losh, S. C., Wilke, R., Pop, M. (2008) Some methodological issues with "Draw a Scientist Tests" among young children. International Journal of Science Education, 30(6), 773-792. doi:10.1080/09500690701250452

Maoldomhnaigh, M. Ó., Hunt, Á. (1988) Some factors affecting the image of the scientist drawn by older primary school pupils. Research in Science and Technological Education, 6, 159166.

Maoldomhnaigh, M. Ó., Mhaoláin, V. N. (1990) The perceived expectation of the administrator as a factor affecting the sex of scientists drawn by early adolescent girls. Research in Science and Technological Education, 8, 69-74.

McCann, F. F., Marek, E. A. (2016) Achieving Diversity in STEM: The Role of DrawingBased Instruments. Creative Education, 7(15), 2293-2304. doi:10.4236/ce.2016.715223

Mead, M., Métraux, R. (1957) Image of the scientist among high-school students. A pilot study. Science, 126(3270), 384-390.

Medina-Jerez, W., Middleton, K. V., Orihuela-Rabaza, W. (2011) Using the DAST-C to explore Colombian and Bolivian Students' Images of scientists. International Journal of Science and Mathematics Education, 9(3), 657-690. doi:10.1007/s10763-010-9218-3

Newton, L. D., Newton, D. P. (1998) Primary children's conceptions of science and the scientist: Is the impact of a national curriculum breaking down the stereotype? International Journal of Science Education, 20(9), 1137-1149. doi:10.1080/0950069980200909

Özel, M. (2012) Children's images of scientists: Does grade level make a difference? Kuram ve Uygulamada Egitim Bilimleri, 12(SUPPL. 4), 3187-3198.

Özgelen, S. (2012) Turkish Young Children's Views on Science and Scientists. Educational Sciences: Theory \& Practice - Special Issue, Autumn(Special Issue), 3211-3225.

Reinisch, B., Krell, M., Hergert, S., Gogolin, S., Krüger, D. (2017) Methodical challenges concerning the Draw-A-Scientist Test: a critical view about the assessment and evaluation of learners' conceptions of scientists. International Journal of Science Education, 39(14), 1952-1975. doi:10.1080/09500693.2017.1362712

Ruiz-Mallén, I., Escalas, M. T. (2012) Scientists Seen by Children: A Case Study in Catalonia, Spain. Science Communication, 34(4), 520-545. https://doi.org/10.1177/1075547011429199

Türkmen, H. (2008) Turkish primary students' perceptions about scientist and what factors affecting the image of the scientists. Eurasia Journal of Mathematics, Science and Technology 
Education, 4(1), 55-61.

Vázquez, Á., Manassero, M. A. (1998) Dibuja un científico: imagen de los científicos en estudiantes de secundaria. Infancia Y Aprendizaje, 21(81), 3-26. doi:10.1174/021037098320825226

Zhai, J., Jocz, J. A., Tan, A. L. (2014) “Am I Like a Scientist?”: Primary children's images of doing science in school. International Journal of Science Education, 36(4), 553-576. doi:10.1080/09500693.2013.791958 